\title{
ASPECTOS DO MANEJO REPRODUTIVO DE SUÍNOS
}

Ronaildo Fabino Neto; João Paulo Belém de Sousa; Letícia Fernandes Xavier Costa; Danyane Pereira Marques; Ingrid Lorrainy da Silva Oliveira; Isadora Cristina Alves Silva; Marcelo Marcondes de Godoy, Flávia Oliveira Abrão Pessoa

Instituto Federal Goiano Campus Ceres, Ceres, GO. E-mail: ronaildo.neto@ifgoiano.edu.br

\section{RESUMO}

Essa revisão foi realizada com o objetivo de descrever os principais manejos reprodutivos empregados na criação dos suínos. Atualmente a suinocultura no Brasil tem parâmetros produtivos médios de 9,5 leitões/parto com 1,9 parto/ano, tendo um potencial genético para chegar 13 leitões/parto com 2,6 parto/ano. Para obtenção destes índices zootécnicos na produção de suínos, é necessário investir em tecnologias reprodutivas como a inseminação artificial, instalações adequadas e treinamento frequente da mão de obra. Nesse sentido, para se ter sucesso na reprodução, torna se necessário conhecer a anatomia e fisiologia do sistema reprodutivo masculino e feminino. $\mathrm{O}$ bom desempenho reprodutivo dos animais depende ainda, do critério de seleção do varrão e das matrizes aplicado na criação. É fundamental conhecer o ciclo estral, bem como, o comportamento da porca em estro para obter sucesso na inseminação artificial ou monta natural. O período de gestação, assim como o parto, são fases críticas na criação e devem ser bem conduzidas com o intuito de evitar ou diminuir a mortalidade dos leitões. Portanto, as fases reprodutivas dos suínos devem ser bem conduzidas com atenção especial ao manejo alimentar e sanitário. O conhecimento do manejo reprodutivo por parte do produtor e/ou técnico responsável pela granja é de fundamental importância para alcançar bons índices produtivos.

Palavras - chave: reprodução de suínos; gestação de suínos; suinocultura; desempenho reprodutivo

\section{ASPECTS OF THE REPRODUCTIVE MANAGEMENT PRACTICES OF SWINE}

\begin{abstract}
This review was carried out with the purpose of describing the main reproductive management used in the rearing of pigs. Currently, swine breeding in Brazil has average production parameters of 9.5 piglets / calving with 1.9 calving / year, with a genetic potential to reach 13 piglets / calving with 2.6 calving / year. To obtain these zootechnical indexes in pig production, it is necessary to invest in reproductive technologies such as artificial insemination, adequate facilities and frequent training of the workforce. In this sense, to be successful in reproduction, it becomes necessary to know the anatomy and physiology of the male and female reproductive system. The good reproductive performance of the animals also depends on the criterion of selection of the boar and the matrices applied in the breeding. It is fundamental to know the estrous cycle, as well as, the behavior of the nut in estrus to obtain success in artificial insemination or natural mating. The gestation period, as well as childbirth, are critical breeding phases and should be well conducted with the aim of avoiding or reducing piglet mortality. Therefore, the reproductive stages of pigs should be well conducted with special attention to food and sanitary management. The knowledge of the reproductive management by the producer and / or technician responsible for the farm is of fundamental importance to achieve good productive indexes.
\end{abstract}

Keywords: reproduction of pig; swine breeding; swine breeding; performance 


\section{INTRODUÇÃO}

Entre os anos de 1995 e 2012 o rebanho mundial de suínos cresceu 4,4\%, passando de 900 para 940 milhões de cabeças. Ao ser observado a produção por país verifica-se que a China é o maior produtor mundial, sendo detentor de 50,5\% do total e o Brasil ocupa neste ranking o terceiro lugar em número de cabeças com 4,2\% do plantel mundial (FERREIRA et al., 2014).

Atualmente, a suinocultura é uma das atividades da agropecuária mais difundida e produzida no mundo. Os suínos já eram criados há mais de 5.000 anos, e ainda constituem um dos ramos de grande importância. A espécie foi introduzida na América por Cristóvão Colombo em 1942. No Brasil, foram trazidos por Martim Afonso de Sousa em 1532, quando fundou São Vicente no litoral paulista (GERVÁSIO, 2013).

Devido a esse crescimento exponencial, a atividade vem exigindo cada vez mais profissionais qualificados que consigam produzir em maior quantidade, carne de boa qualidade que atenda a demanda mundial. Para isso, a suinocultura carece de conhecimento e a especialização destes profissionais, buscando assim, sempre as inovações tecnológicas que possam aumentar a eficiência reprodutiva, e tornar possível o melhoramento genético da espécie em questão (FERREIRA et al., 2014).

Segundo Rosa et al. (2014), no sul do país, em criações tecnificadas de pequeno a médio porte, os índices reprodutivos médios estão em 9,5 leitões/leitegada e 1,9 partos/porca/ano, enquanto o potencial biológico estimado das fêmeas suínas está por volta de 13 leitões/leitegada e 2,6 partos/porca/ano. Isso mostra que existe uma margem considerável entre os resultados e o potencial genético disponível.

Quanto maior o número de leitões nas maternidades, mais animais chegarão no setor de terminação. Para que seja possível uma produção elevada de leitões, além da genética da fêmea e do varrão utilizado para fazer as doses inseminantes, interessa o modo e a altura como a inseminação artificial (IA) é realizada; sendo assim, a IA é um dos fatores condicionantes de todo o processo produtivo da suinocultura, pois o sucesso reprodutivo é dependente deste (SENA, 2011).

Objetiva se com esse trabalho realizar uma breve revisão de literatura abordando o manejo reprodutivo dos suínos incluindo tanto a fisiologia quanto a anatomia destes animais.

\section{ANATOMIA DO SISTEMA REPRODUTOR DO MACHO E DA FÊMEA SUÍNA}

Os órgãos do sistema reprodutor dos suínos são formados por segmentos contínuos que servem à produção, à maturação e à transferência de células germinativas masculinas.

Segundo Frandson et al. (2011), o sistema reprodutor masculino é composto por dois testículos no escroto, órgãos acessórios, que incluem ductos e glândulas, mais o pênis. Os testículos produzem os espermatozoides e testosterona. O escroto dispõe de um ambiente favorável para a produção e maturação dos espermatozoides. As estruturas restantes ajudam os espermatozoides a alcançarem o óvulo na fêmea. Essas estruturas incluem: o epidídimo e o ducto deferente, as glândulas sexuais acessórias (glândulas apolares, glândulas vesiculares, a próstata e as glândulas bulbouretrais), a uretra e o pênis.

De acordo com Reece (2014), as funções reprodutivas da fêmea são a produção de oócitos e o fornecimento de um ambiente para o crescimento e nutrição do feto que se desenvolverá após a fertilização de um oócito maduro por um espermatozoide.

Os órgãos reprodutivos femininos incluem dois ovários, duas tubas uterinas, o útero, a vagina e a vulva. O óvulo é liberado do ovário e entra na extremidade aberta da tuba uterina, onde normalmente ocorre a fertilização, devido a passagem do óvulo para o útero. No útero, o zigoto desenvolve-se em um embrião, e em seguida um feto, e por fim passa para fora do útero através da vagina e da vulva como um recém-nascido (FRANDSON et al., 2011). 
MANEJO REPRODUTIVO DO MACHO

Seleção dos machos

O macho contribui com $50 \%$ do material genético do plantel de produção, e pelo fato de servir aproximadamente para 20 fêmeas na monta natural, sua importância individual na produção torna-se ainda maior. Por essa razão, a escolha do macho tem uma influência decisiva nos resultados econômicos da produção (FERREIRA, 2012).

\section{Idade}

Os reprodutores machos devem ser repostos a uma taxa nunca inferior a $50 \%$ ao ano, o que equivale utilizar os machos na reprodução por um período máximo de dois anos, para que, dessa forma, o produtor possa se beneficiar das melhorias genéticas e obter ganhos econômicos com a exploração suinícola (FERREIRA, 2012).

O produtor deve adquirir um novo macho com idade aproximada de cinco meses, no mínimo três meses de antecedência à previsão de uso no rebanho. Isto porque o macho deve passar por um período de adaptação ao novo ambiente, além do tempo necessário para atingir sua maturidade sexual e o devido treinamento para sua função reprodutiva dentro do plantel (FÁVERO, 1997). Segundo Ferreira (2012), treinamento dos machos deve ocorrer a partir de 5,5 a 7,5 meses de idade.

\section{Cuidados com machos}

Ao chegar ao seu novo ambiente, o macho deve ser alojado em uma baia limpa, desinfetada, confortável, com área mínima de seis $\mathrm{m}^{2}$, acesso à água e separado dos outros animais da propriedade, por um período mínimo de quatro semanas (FERREIRA, 2012). Segundo Fávero \& Irgang (1997), o piso da baia não deve ser liso nem abrasivo e de preferência com cama de maravalha de forma a evitar danos aos aprumos.

A alimentação deve ser fornecida diariamente, em torno de $2 \mathrm{~kg}$ de ração, dividida em duas refeições, com o intuito de evitar que os cachaços engordem em demasia. Em épocas de trabalho mais intenso, a quantidade diária de ração pode ser aumentada, sempre levando em consideração física do macho (FERREIRA, 2012).

\section{Exame andrológico}

Segundo UFLA (2008), no exame andrológico a capacidade reprodutiva do macho suíno vai ser averiguada, por técnicos capacitados, através dos diversos processos realizados na prática do "Exame andrológico", que são:

\section{Identificação do animal}

Deve ser verificada a procedência, data de nascimento, linhagem peso e filiação dos animais de machos de suínos, para obter melhores resultados nos cruzamentos (OBERLENDER et al., 2013).

\section{Realização de exames clínicos}

\section{Análise ou histórico clínico do animal}

Deve contemplar dados relativos ao animal e ao rebanho, o tipo de manejo a que estão submetidos os animais e também outras informações tais como: regime de atividade sexual (se realiza monta natural ou se é doador de sêmen para inseminação artificial); frequência de ejaculação; número de fêmeas cobertas pelo reprodutor; número de fêmeas gestantes e índice de retorno ao cio (OBERLENDER et al., 2013). 


\section{Exame clínico geral}

Inspeção do animal estacionado e em movimento, avaliando os sistemas nervoso, respiratório, circulatório, digestório e locomotor, com verificação das condições dos aprumos, articulações e cascos e da condição corporal. Caso seja percebida alguma alteração num dos sistemas, o exame deve ser aprofundado devendo ser dada uma atenção especial aos defeitos hereditários (OBERLENDER et al., 2013).

\section{Exame do sistema reprodutor}

Para órgãos externos utiliza-se a inspeção e palpação, podendo ser complementado com ultrassonografia. Verificam-se as dimensões, a consistência, a simetria e a mobilidade das partes do sistema genital, além da compatibilidade com o desenvolvimento corporal e idade. Os órgãos examinados no reprodutor são: testículos, epidídimos, prepúcio, pênis e genitália interna (UFLA, 2008).

\section{Avaliação do comportamento sexual e índole do reprodutor}

Através da verificação da libido e da execução das fases da cópula (quando um reprodutor está diante de uma ou mais fêmeas em cio). As fases da cópula têm de ser avaliadas separadamente (excitação, aproximação, ereção, protrusão, monta, introdução, propulsão e ejaculação, descida e fim do ato de monta) (UFLA, 2008).

\section{Espermograma}

Consiste na avaliação do sêmen por diversos processos, iniciando pela coleta do mesmo e então avaliando-se as características físicas do ejaculado (volume e aspecto do sêmen; motilidade, vigor e concentração dos espermatozoides) (UFLA, 2008).

\section{Avaliação de características morfológicas dos espermatozoides}

Através do uso de técnicas, como esfregaços corados ou preparação úmida, deve-se observar a quantidade de anormalidades nos espermatozoides e então estimar o número de espermatozoides viáveis no ejaculado (UFLA, 2008).

\section{Exames complementares}

Não são exames obrigatórios e serão realizados a critério do técnico responsável, como: teste de termo resistência, microbiológico e sorológico (UFLA, 2008).

\section{Coleta de sêmen}

Segundo Oberlender et al., (2013), as etapas da coleta de sêmen em suínos são:

- Corte periódico dos pelos existentes ao redor do prepúcio;

- Limpeza da abertura prepucial e área circundante (se necessário) com algodão ou papel toalha descartável;

- Eliminação manual dos fluídos prepuciais antes manipulação peniana;

- Luvas descartáveis para minimizar a contaminação do ejaculado e reduzir o risco de transmissão microbiana entre machos devem sempre ser utilizada pelo operador;

- Durante a coleta, manter posicionamento peniano perpendicular (angulação de 45) ao abdômen do macho para minimizar a possibilidade de que fluidos prepuciais escorram pelo pênis e caiam sobre o ejaculado coletado;

- Eliminação das primeiras frações do ejaculado (fração pré-espermática) antes da realização da coleta;

\section{Monta}

A atividade de monta ou cobertura assim como todas as demais requerem esforço físico, e 
deve ser realizada de maneira a evitar o estresse dos animais. As cobrições devem ser realizadas preferencialmente nas horas mais frescas do dia, início e fim da jornada de trabalho, em locais arejados e com piso antiderrapante. Quanto ao arraçoamento deve ser realizado após a cobertura, possibilitando que os animais estejam com estômago vazio durante o processo (FÁVERO et al., 2003).

Os animais reprodutores não devem ser utilizados tão logo alcancem a puberdade por volta dos 5 meses de idade, uma vez que seu desenvolvimento anatômico ainda não está completo. O ideal é que o macho suíno comece a ser treinado em coberturas por volta dos 7 meses, utilizando uma fêmea plurípara, dócil e que já tenha sido coberta por um macho experiente (FERREIRA et al.; ROSA et al., 2014).

O serviço de cobertura deve ter duração média de 10 a 20 minutos devido o volume do sêmen suíno ser grande $(500 \mathrm{~mL})$ e a uretra muito fina. Este tempo deve ser respeitado, qualquer cobertura com duração inferior deve ser considerada duvidosa. Devido sua ejaculação ser intrauterina sendo recomendado uma média de três coberturas por fêmea (FERREIRA, 2012).

A relação macho:fêmea é recomendável 1:20 a 1:25, dependendo do tipo de manejo de cobertura utilizado na unidade de produção. Segundo Fávero et al., (2003) a frequência de utilização dos machos com idade entre sete a nove meses de idade deve ser de duas montas por semana (1 fêmea coberta); machos entre 10 e 12 meses realizar no máximo quatro montas por semana ( 2 fêmeas cobertas) e machos com idade acima de um ano até seis montas por semana.

\section{Sistemas de monta}

Na suinocultura existem dois sistemas de coberturas que podem ser utilizados de acordo com o manejo e o objetivo da criação: monta livre ou monta controlada.

\section{Monta livre ou natural}

Neste sistema machos e fêmeas ficam todo o tempo juntos em piquetes ou baias. Este sistema não é muito indicado, uma vez que suas desvantagens se sobrepõem as vantagens. As vantagens estão relacionadas com a boa deteç̧ão do cio e altos índices de fertilidade. Já suas desvantagens são: dificuldade de controle zootécnico nem previsão de parto, não identificação dos animais estéreis, os machos disputam as fêmeas em cio e podem brigar até a morte e esgotamento dos varrões pelo aumento da frequência de coberturas (FERREIRA et al.; ROSA et al., 2014; FÁVERO et al.; 2003).

\section{Monta controlada ou dirigida}

É o sistema mais racional e indicado para uma cadeia produtiva tecnificada e intensiva de suínos. Primeiramente tanto o macho quanto a fêmea são higienizados e em seguida a fêmea é conduzida à baia do macho e o tratador acompanhará toda a cobertura auxiliando na inserção do pênis na vagina da porca, caso seja necessário (FERREIRA, 2012).

Neste método o criador terá previsão dos partos, total controle zootécnico, evitando endogamia, permite controle da paternidade e o máximo aproveitamento do varão com máxima eficiência reprodutiva (ROSA et al., 2014).

\section{MANEJO REPRODUTIVO DAS FÊMEAS}

\section{Seleção das fêmeas}

Para as fêmeas que forem selecionadas destinadas a reprodução deve-se garantir que cheguem à puberdade com peso corporal adequado, aclimatadas, imunizadas e com pelo menos um cio detectado. Bons índices reprodutivos na suinocultura relacionam-se com a seleção das fêmeas que farão parte do plantel (FERREIRA et al., 2014).

A seleção deve começar na desmama com uma pré-seleção entre $85-90 \%$ das leitoas, com 
descarte de $10-15 \%$ das que apresentarem menor potencial. A segunda seleção é feita na saída da creche descartando de $10-20 \%$ das fêmeas que chegará ao final do processo com uma taxa de seleção de $65-80 \%$ com descarte de $20-35 \%$ das que apresentaram baixo potencial reprodutivo (FERREIRA et al., 2014).

Segundo Schwarz (2008) a fêmea selecionada como reprodutora deve apresentar algumas características como: boa conformação, perfeitos caracteres raciais, ter idade entre seis e sete meses, temperamento dócil e apresentar perfeito desenvolvimento da vagina e vulva.

\section{Primeira cobertura}

Aconselha-se que as marrãs sejam cobertas com peso viso em torno de $140-150 \mathrm{~kg}$, com idade entre 220 a 240 dias e a partir do 20 cio, dando preferência para o 30 cio. Estudos acurados afirmam que, com essas condições é possível associar a maturidade hormonal das fêmeas as quais apresentam níveis adequados de tecido magro e gordura proporcionando elevado número de ovulações e capacidade uterina adequada para gestar um grande número de fetos (DIAS et al., 2011).

\section{Cio}

Na espécie suína, podem acontecer cios em diferentes períodos fisiológicos. O cio normal, que é aquele em que a fêmea estará apta a conceber e manter a gestação; o cio silencioso, quando as fêmeas ovulam e não apresentam os sintomas de cio; o cio ocorrente cerca de 60 horas após o parto, sendo este infértil e que não deve ser aproveitado; e o cio falso ou de "encabelamento", que ocorre em cerca de $5 \%$ do rebanho e se manifesta por volta do 60 dia de gestação, que também não deve ser aproveitado (FERREIRA 2012).

Recomenda-se realizar de duas a três coberturas ou inseminações no período do cio, pois não se sabe o momento com precisão da ocorrência da ovulação. Manter intervalo de 24 horas entre montas naturais e de $12 \mathrm{~h}$ à $24 \mathrm{~h}$ entre inseminações artificiais. Os fatores que podem influenciar a taxa de ovulação da fêmea são: idade, endogamia, nutrição, estádio fisiológico e número de cobrições (ROSA et al., 2014; FERREIRA, 2012).

Quanto a idade a quantidade de óvulos aumenta até o 5ㅇ ou 6 cio, depois ocorre uma queda na produção. $O$ fator endogamia causa uma redução na taxa de ovulação sendo indicado a utilização do cruzamento que evita a queda e garante um maior vigor dos descendentes (FERREIRA 2012).

Quanto a condição nutricional pode ser verificada por avaliações visuais pela condição corporal das fêmeas. Recomenda-se que as matrizes estejam com escore entre dois e três e evitar um escore entre 4 e 5 . O estádio fisiológico das fêmeas em lactação, não permite que ovulam e aquelas que foram cobertas mais vezes apresentam maior taxa ovulação (FERREIRA, 2012).

\section{Inseminação artificial}

As instalações para realização da IA em suínos devem ser estruturadas de modo a garantir um manejo tranquilo e seguro, tanto para os animais quanto para os operadores. As instalações necessárias são: sala de pré-coleta, sala para coleta e laboratório. A sala de pré-coleta será o local para higienização dos machos, está deverá ser próxima a sala de coleta que deve possuir uma área entre 8 e $12 \mathrm{~m}^{2}$ e dispor de locais de fuga para o operador (DIAS et al., 2012).

De acordo com Ferreira (2012) o laboratório deverá ter uma janela de comunicação com a sala de coleta por onde será transferido o sêmen coletado. O laboratório deverá dispor de microscópio para avaliação da qualidade e contagem dos espermatozoides, estufa (15 a 17으 C) para conservação das doses e de banho-maria para manter aquecido os matérias necessários a coleta e o sêmen recém coletado.

Silveira et al., (2005) relata as etapas que devem ser seguidas para realização da IA: 
- Primeiramente deve-se realizar a higienização da região vulvar em seguida a pipeta já pode ser desembrulhada e lubrificada com o próprio sêmen ou um gel lubrificante apropriado;

- Então abre-se os lábios vulvares e introduz-se a pipeta na direção dorso-cranial com movimentos anti-horários até que ela fixe a cérvix. Isto resultará em estímulos do trato reprodutivo o que minimizará o refluxo do sêmen;

- Agora a bisnaga com o sêmen deve ser acoplada, sendo feita uma leve pressão no dorso da fêmea para que este seja introduzido no útero e assim ocorra o transporte e absorção;

- A IA deve ter duração de no mínimo cinco minutos, após este período a pipeta deve ser retirada num ângulo de 45 por movimentos no sentido horário e manter a porca por mais 5 ou 10 minutos próximo ao macho para garantir melhores índices de fertilidade.

Para suínos adotam-se dois tipos de inseminação artificial a tradicional já descrita anteriormente e a intrauterina. De acordo com Bortolozzo et al., (2005) , a inseminação intrauterina realiza a deposição não cirúrgica da dose do sêmen diretamente no lúmen uterino. Watson e Behan (2002) descreve que para essa técnica é utilizado um cateter que desliza pelo interior da pipeta tradicional, passa pela cérvix e é introduzido até 20 a $25 \mathrm{~cm}$ no corpo uterino. Essa técnica permite a redução no número de espermatozoides e no volume da dose do inseminante usado na IA (TONUILLI, 2010).

\section{Gestação}

A porca matriz passa dois terços de sua vida no período de gestação, demonstrando assim, a importância do manejo nesta fase quando visamos aumentar a produtividade (FERREIRA et al., 2014).

A preocupação com a gestação das porcas, inicia-se com a identificação da prenhez. Na suinocultura tecnificada é fundamental a redução dos intervalos entre partos, com objetivo de se aumentar o número de leitegadas por ano. A técnica de identificação da prenhez das porcas é fundamental para elevar a produtividade média de uma granja para próximo do ideal que está por volta de 14 leitões por porca/parto e uma média de três partos anos (FERREIRA et al., 2014).

Segundo Camargo et al. (2017) o período de gestação pode ser realizado em gaiolas individuais ou em baias coletivas. Durante o período de gestação, a porca não pode se estressar devendo ter o máximo de conforto possível principalmente nos 30 primeiros dias. 0 uso de baias coletivas subdivida em baias de fugas com máquina de controle de alimentação automática e a fase de gestação ao ar livre está sendo adotado para reduzir os sinais de estresse (SILVA et al., 2008).

\section{Confirmação da prenhez}

Para a identificação precoce da gestação Rosa et al. (2014) sugere quatro métodos bastante usados na suinocultura, são eles: (1) controle do retorno ao cio - que consiste reaparecimento do cio, podendo ser normal ou não. É feita com o auxílio de um varrão utilizando os mesmos procedimentos para a identificação do cio, tendo alta aplicabilidade com precisão de $84 \%$ até os 25 dias após a inseminação; (2) prova de sulfato de estrona - que é baseado na detecção desta substância, produzida pela placenta entre 16 a 35 dias de gestação; (3) ultrassonografia - que pode fornecer resultado seguros a partir de 21 dias, porém é muito caro sendo mais aplicado em pesquisas e (4) palpação retal - chegando a ter até $90 \%$ de precisão em porcas com peso acima $150 \mathrm{~kg}$, devendo ser realizado com o uso de luvas e substâncias lubrificantes.

\section{Período da gestação}

O período médio de gestação é de 114 dias podendo variar de 112 a 116, sendo considerando aborto qualquer parto antes de 110 dias de gestação e nenhum dos neonatos 
sobreviver além de 24 horas (ROSA et al., 2014).

O período de gestação da porca pode ser dividido em três partes, o primeiro período é o mais crítico de sobrevivência do embrião com baixo crescimento fetal, o segundo período está associado com o desenvolvimento mamário e a formação do esqueleto, e por fim o último período que é referente a fase de desenvolvimento fetal (UFLA, 2008).

Segundo Ferreira et al. (2014), durante todo o período de gestação, a porca deve ser alimentada por um programa que atende as exigências nutricionais de cada fase da gestação. $A$ alimentação de uma fêmea em período de gestação deve garantir a mantença, o crescimento do tecido muscular, a reposição de reserva de gordura e musculatura utilizadas durante a lactação e o crescimento fetal dos leitões.

\section{Transferência para maternidade}

É extremamente recomendado que a matriz seja conduzida para a maternidade com um tempo mínimo de cinco dias antes do parto fim de que ela se adapte as novas instalações. Antes de ser levada para a maternidade a fêmea deve ser submetida ao um banho de desinfecção com uso de água, sabão e escova para remoção de possíveis fontes de contaminação (BRAGA et al., 2013).

\section{Parto}

Ferreira (2014) relatam que a hora do parto é com certeza o momento mais importante dentro de uma granja, pois qualquer erro pode gerar queda na eficiência reprodutiva da matriz e dos leitões causando prejuízo ao criador. Guido (2005), ressalta que a identificação do parto pode ser observada pela mudança no comportamento, sendo a melhor forma de detectar a aproximação do parto é por meio da observação da vulva e principalmente da glândula mamária.

\section{Duração do parto}

Segundo Fávero et al. (2003) um parto pode durar de duas a seis horas, se exceder este tempo, é considerado como parto distócico devendo ocorrer a interferência do manejador caso a porca não apresentar contrações, atraso e sem início de nascimento dos leitões após 20 minutos. Essa interferência deve ser feita preferencialmente com porcas pesando acima de $150 \mathrm{~kg}$.

Fêmeas pluríparas apresentam em média menor intervalo de expulsão de um leitão para o outro, em torno de 16 a 20 minutos, e fêmeas primíparas apresentam intervalos maiores, entre 20 e até uma hora. Tempo superior a este devem ser feitos os procedimentos relatados anteriormente (ANTUNES, 2007).

\section{CONSIDERAÇÕES FINAIS}

O estudo do manejo reprodutivo é de suma importância para elevar os índices produtivos do plantel. Para realizar este manejo o responsável pela criação deve ser conhecedor dos aspectos reprodutivos que caracterizam a espécie que incluem conhecimentos da anatomia e fisiologia destes animais, nutrição, ambiência e sanidade.

\section{REFERÊNCIAS}

ALMEIDA, M. J. M. Suinocultura. Setor de ensino a distância. Barbacena - MG, 2011. Disponível em: <http://pt.slideshare.net/vet2011/sunocultura>. Acesso em: 26 de fevereiro de 2017.

ANTUNES, R.C. Manejo reprodutivo de fêmeas pós-desmame com foco sobre o intervalo desmame cio (IDC). Rev. Bras. Reprod. Anim., Belo Horizonte, v.31, n.1, p.38-40, 2007.

BORTOLOZZO, F. P.; WENTZ, I.; DALLANORA, D. Situação atual da inseminação artificial em suíno. 
Acta Scientiae Veterinária. v. 33, n. 1, p. 17-32, 2005.

BRAGA, L. S.; COSTA, L. F.; CAMPOS, P. M. Principais fatores de interferência nos índices zootécnicos reprodutivo das fêmeas suínas. 2013. 49 f. Trabalho de conclusão de curso (Medicina Veterinária) - Pontifícia Universidade Católica. Betim.

CAMARGO, J. C. M.; OLIVEIRA, J. E. F.; OLIVEIRA, R. C. V. Animais sadios e menores custos com o sistema semi-intensivo na suinocultura. Informativo Técnico na 301. Disponível em: <http://www.sossuinos.com.br/Tecnicos/info301.htm>. Acessado em>: 20 de nov. de 2014.

DIAS, A. C.; CARRARO, B. Z.; DALLANORA, D.; COSER, F. J.; MACHADO, G. S.; MACHADO, I. P.; PINHEIRO, R.; ROHR, S. A. Manual Brasileiro de Boas Práticas Agropecuárias na Produção de Suínos. Brasília: Editora ABCS. Concórdia: Embrapa Suínos e Aves, 2011. Disponível em:< http://www.majop.com.br/27012012124348manual_brasileiro.pdf >. Acesso em: 26 de fevereiro de 2017.

FÁVERO, J. A.; KUNZ, A.; GIROTTO, A. F.; MONTICELLI, C. J. KICH, J. D.; LUDKE, J. V.; MORÉS, N.; ABREU, P. G.; SILVEIRA, P. R. S. Produção Suínos. Embrapa Suínos e Aves. Sistema de Produção, 2003. Disponível em: <http://www.cnpsa.embrapa.br/SP/suinos/autores.html>. Acesso em: 26 de fevereiro de 2017.

FÁVERO, J. A. \& IRGANG, R. O reprodutor suíno macho. Concórdia Suínos e Aves: Instruções Técnica para Suinocultura. 2 p., 1997.

FRANDSON, R.D.; WILKE, W.L.; FAILS, A.D. Anatomia e Fisiologia dos Animais de Fazenda. 7ạed. Rio de Janeiro: Editora Guanabara Koogan, 2011.

FERREIRA, R. A. Suinocultura: manual prático de criação. Viçosa, MG: Editora Aprenda Fácil, 1ำed. 443p., 2012.

FERREIRA, A. H.; CARRARO, B.; DALLANORA, D.; MACHADO, G.; MACHADO, I. P.; PINHEIRO, R.; ROHR, S. Produção de suínos: teoria e prática. Coordenação editorial: Associação Brasileira de Criadores de Suínos; Coordenação Integral Soluções em Produção Animal. 908 p. Brasília - DF, 2014.

GERVÁSIO, E.W. Suinocultura - Análise da Conjuntura Agropecuária. SEAB - Secretaria de Estado da Agric ultura e do Abastecimento. DERAL - Departamento de Economia Rural. 2013. Disponível em:<http://www.agricultura.pr.gov.br/arquivos/File/deral/Prognosticos/SuinoCultura_2012_2013 .pdf>. Acesso em: 26 de fevereiro de 2017.

GUIDO, M. C. Diagnóstico de gestação nas fêmeas domésticas. 2005. Disponível em: <http://eagaspar.com.br/mcguido/diag__gestacao.htm>. Acesso em: 26 de fevereiro de 2017 Oberlender, G.; ZANGeronimo, M. G.; SilvA, A. C.; MENEZES, T. A.; PONTElO, T. P. Bacteriologia do sêmen suíno - aspectos relacionados: revisão de literatura. Revista Científica Eletrônica de Medicina Veterinária, v. 1, n. 20, p. 1-15, 2013.

SENA, A. L. G. Condução da Reprodução em suínos: Análise Zootécnica e Estudo Comparativo de Técnicas de Inseminação Artificial.2011. Dissertação de Mestrado em Engenharia Zootécnica/Produção Animal - Instituto Superior de Agronomia, Universidade Técnica de Lisboa, 
Lisboa,

2011.

Disponível

em:

<http://www.repository.utl.pt/bitstream/10400.5/4077/1/Condu\%C3\%A7ao\%20da\%20reprodu\% C3\%A7ao\%20em\%20suinos.pdf>. Acesso em: 26 de fevereiro de 2017.

REECE, W.O. Anatomia Funcional e Fisiologia dos Animais Domésticos. 3ạed. São Paulo: Editora Roca, 2014.

ROSA, L. S.; COSTA FILHO, L. C.C.; SOUZA, M. I. L.; CORREIA FILHO, R. A. C. Fatores que afetam as características produtivas e reprodutivas de fêmeas suínas. B. Indústr. Anim. v. 71, n. 4, p. 380395, 2014.

SILVA, I. J. O.; PANDORFI, H.; PIEDADE, S. M. S. Influência do sistema de alojamento no comportamento e bem-estar de matrizes suínas em gestação. R. Bras. Zootec. v. 37, n. 7, p. 13191329, 2008. https://doi.org/10.1590/S1516-35982008000700025

SCHWARZ, L. R. Seleção de reprodutores suínos. Lavras: Editora UFLA. Boletim Técnico no 81, p. 114, 2008. Disponível em: < http://livraria.editora.ufla.br/upload/boletim/tecnico/boletim-tecnico81.pdf>. Acesso em: 26 de fevereiro de 2017.

SILVEIRA, P. R. S.; SCHEID, I. R.; CRESTANI, A. M. Inseminação artificial de suínos: um guia para os produtores. Concórdia: Embrapa Suínos e Aves, 2005.

SILVEIRA, P.R.S. \& WENTZ, I. Anestro e cio silencioso em porcas desmamadas. EMBRAPA. S/D. Disponível em: <http://www.cnpsa.embrapa.br/sgc/sgc_publicacoes/cot104.pdf> Acesso em: 26 de fevereiro de 2017.

TONIOLLI, R. Recentes avanço na tecnologia de sêmen e em inseminação artificial em suínos. Rev. Bras. Reprod. Anim. v. 34, n. 2, p. 105-113, 2010.

UNIVERSIDADE FEDERAL DE LAVRAS - UFLA. Seleção de reprodutores suínos. Lavras: Editora UFLA, n. .91, p. 1-14, 2008.

WATSON, P. F.; BEHAN, J. R. Intrauterine insemination of sows with reduced sperm numbers: results of a commercially based field trial. Theriogenology, v.57, p.1683-1693, 2002. https://doi.org/10.1016/S0093-691X(02)00648-9 